\title{
RANKING OF ENTERPRISES WITH REGARD TO INDUSTRIAL MATURITY LEVEL USING AHP AND TOPSIS
}

*Note: Do not include the author(s) names and information as this document will be blind reviewed and they will be entered during proposal submission.

\begin{abstract}
The project Innovative Smart Enterprise INSENT wants to improve the scientific understanding of average Croatian manufacturing enterprise by promoting empirical enterprise-level research on technological and non-technological process and organizational innovation. It will help develop a regional model of innovative smart enterprise based not just on state-of-the-art theoretical models, but also on state-of-the-art practical models like Lean Management philosophy from Toyota Production System. Evaluation of industrial maturity level research is carried out using Web questionnaires and interviews with 38 CEOs (chief executive officer) of manufacturing enterprises. The problem of industrial enterprises evaluation is solved by a model that combines Analytical Hierarchy Process (AHP) and Technique for Order Preference by Similarity to Ideal Solution (TOPSIS).
\end{abstract}

Keywords: Industry 4.0, industrial maturity level, AHP, TOPSIS

\section{Introduction}

An application of the Internet of Things and Services into the manufacturing environment is ushering in the fourth industrial revolution: Industry 4.0. For every industrial enterprise it is important to know its maturity level, or to find out how close it is to Industry 4.0.

\section{Literature Review}

The main information about Industry 4.0 are presented in the paper by Kagermann, Wahlster and Helbig (2013), while the main points of AHP and TOPSIS method can be found in Saaty (2005) and Yoon and Hwang (1995).

\section{Objectives}

In this research the main goal is to calculate industrial maturity level of Croatian enterprises. For this purpose at the first level of hierarchy the importance of three criteria is analysed: technique (criterion B1), organization (criterion B2) and personnel (criterion B3) while on the second level five of their most important elements (subcriteria C1-C15) are analysed. With the intention to obtain significant data 38 best enterprises are selected and the interviews with their CEOs and technical directors are conducted.

\section{Research Design/Methodology}

A model that combines AHP and TOPSIS method solves the problem of industrial enterprises evaluation. After choosing the enterprises to be analysed i.e. determining a set of alternatives, the next step is to choose the criteria with which the analysis will be performed (B1-B3, and C1-C15).

In each of 38 enterprises pairwise comparisons for the three main criteria are carried out to obtain 38 different matrices. The final comparisons are calculated as geometrical mean 
and these data are entered in the Expert Choice to obtain the weights (importance) for the three main criteria (B1, B2 and B3). After that, for each enterprise, based on a survey conducted in the project INSENT, multiple paired comparisons are obtained for every group of subcriteria. Since in each group there are five subcriteria, for each enterprise three matrices of multiple paired comparisons are obtained, i.e. we have 114 matrices. Finally, for every group of subcriteria (C1-C5, C6-10, C11-C15) geometric mean is calculated and the resulting matrices are entered in the Expert Choice. The Figure 1 presents the final weights for the three basic criteria and fifteen subcriteria.

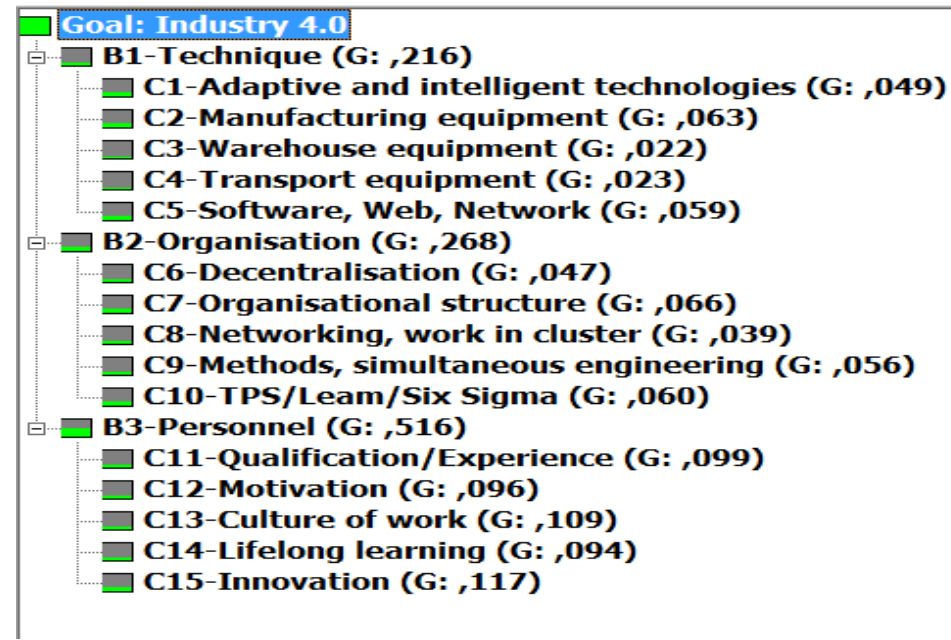

Figure 1. Final weights for basic criteria and subcriteria

These weights are used in the TOPSIS method, and for each enterprise the relative closeness index is calculated to obtain the final ranking of enterprises regarding the requirements of Industry 4.0.

\section{Conclusions}

In order to determine the rank of the company in relation to industrial maturity level AHP and TOPSIS methods are used. Considering the three main criteria: technique, organization and personnel as well as the fifteen subcriteria, thirty-eight enterprises are ranked according to their relative closeness index.

\section{Acknowledgement}

This work has been fully supported by the Croatian Science Foundation under the project Innovative Smart Enterprise - INSENT (1353).

\section{Key References}

Kagermann, H., Wahlster, W. and Helbig J. (2013) Recommendations for implementing the strategic initiative INDUSTRIE 4.0. Heilmeyer und Sernau.

Saaty, T.L. (2005) Theory and Application of the Analytic Network Process. Pittsburgh, PA: RWS Publications.

Yoon, K.P. and Hwang, C-L. (1995) Multiple Attribute Decision Making: An

Introduction. Sage Publications 